\title{
PLAZAS VECINALES DE CULTURA FÍSICA/PLAZAS DE DEPORTES. “TEMPLOS LAICOS” DE LA CIUDAD BATLLISTA DE MONTEVIDEO (1911-1918)
}

\author{
Inés Scarlato García \\ ISEF/Udelar - Uruguay \\ inescarlato@gmail.com
}

\begin{abstract}
RESUMEN
Se analiza el proyecto "Plazas Vecinales de Cultura Física" inaugurado en el año 1913 en Montevideo, liderado por el primer Presidente de la Comisión Nacional de Educación Física (CNEF), Juan Arturo Smith. Se analiza su inscripción en el marco de las políticas reformistas que impulsa el sector político liderado por José Batlle y Ordóñez durante las primeras dos décadas del siglo XX, y el lugar de estas plazas como nuevos "templos laicos" en la proyectada ciudad "batllista". Se destacan elementos que se pretendieron distintivos y superadores respecto a los Playgrounds norteamericanos así como algunas de las influencias recibidas por el movimiento de Asociaciones Cristianas de Jóvenes norteamericano. Se trabaja con documentos y actas de sesión de la CNEF de su período fundacional (1911-1918).
\end{abstract}

Palabras clave: Plazas Vecinales de Cultura Física. Plazas de Deportes. Montevideo.

\section{"PLAZAS VECINALES DE CULTURA FÍSICA"/"PLAZAS DE DEPORTES". "SECULAR TEMPLES" OF THE CITY BATLLISTA OF MONTEVIDEO (1911-1918)}

\begin{abstract}
It analyses the project "Squares Vecinales of Physical Culture" inaugurated in the year 1913 in Montevideo, led by the first President of the National Commission of Physical Education (CNEF), Juan Arturo Smith. It analyses his registration in the frame of the reformist politics that promotes the political sector led by José Batlle y Ordóñez during the first two decades of the 20th century, and the place of these squares like new "secular temples" in the projected city "batllista". They stand out elements that pretended distinctive and superadores with regard to the Playgrounds North American as well as some of the influences received by the movement of Christian Associations of North American Youngsters. It works with documents and records of session of the CNEF of his foundational period (1911-1918).
\end{abstract}

Keywords: Plazas Vecinales de Cultura Física. Plazas de Deportes. Montevideo.

\section{“PLAZAS VECINALES DE CULTURA FÍSICA"/“PLAZAS DE DEPORTES". “TEMPLOS LAICOS” DA CIDADE BATLLISTA DE MONTEVIDÉU (1911-1918)}

\section{RESUMO}

Analisa-se o projeto "Plazas Vecinales de Cultura Física" inaugurado no ano 1913 em Montevideo, liderado pelo primeiro Presidente da Comissão Nacional de Educação Física (CNEF), Juan Arturo Smith. Analisa-se sua inscrição no marco das políticas reformistas que impulsiona o setor político liderado por José Batlle y Ordóñez durante as primeiras duas décadas do século XX, e o lugar destas praças como novos "templos laicos" na projetada cidade "batllista". Destacam-se elementos que se pretenderam distintivos e superadores com respeito aos Playgrounds norte-americanos bem como algumas das influências recebidas pelo 
movimento de Associações Cristãs de Jovens norte-americano. Trabalha-se com documentos e atas de sessão da CNEF de seu período fundacional (1911-1918).

Palavras-chave: Plazas Vecinales de Cultura Física. Plazas de Deportes. Montevidéu.

\section{RÉSUMÉ}

Il s'analyse le projet "Plazas Vecinales de Cultura Física" inauguré dans l'an 1913 à Montevideo, dirigé par le premier Président de la Commission Nationale d'Éducation Physique (CNEF), Juan Arturo Smith. Il s'analyse son inscription dans le cadre des politiques reformistas que stimule le secteur politique dominé par José Batlle y Ordóñez pendant les premières deux décennies du siècle XX, et le lieu de ces places comme nouveaux "temples laïques" dans la projetée ville "batllista". Ils se soulignent des éléments qu'ils s'ont prétendus distinctifs et superadores à l'égard des Playgrounds nord-américains ainsi que quelques des influences reçues par le mouvement d'Associations Chrétiennes de Jeunes nord-américain. Il se travaille avec des documents et des actes de séance de la CNEF de sa période constitutive (1911-1918).

Mots-clés: Plazas Vecinales de Cultura Física. Plazas de Deportes. Montevideo.

\section{INTRODUCCIÓN}

En el presente artículo se exponen algunos de los resultados de una investigación desarrollada ${ }^{1}$ donde se analizó la creación de la primera "plaza vecinal de cultura física" en el año 1913 en Montevideo, instalada por la Comisión Nacional de Educación Física (CNEF) durante el gobierno de José Batlle y Ordóñez², como punto de partida de una política que se replica en todo el territorio uruguayo y se reedita hasta la actualidad bajo la denominación de Plazas de Deporte. Una de las hipótesis que guió este trabajo fue analizar esta política como parte de las condiciones históricas, políticas y culturales que dieron lugar a la emergencia de un saber sobre el tiempo libre en las primeras décadas del siglo XX, que tuvo su traducción en un saber sobre el cuerpo.

En esta oportunidad, se exponen algunos elementos constitutivos de esta política de instalación de "espacios populares de cultura física" en la ciudad de Montevideo bajo los ideales

\footnotetext{
${ }^{1}$ Desarrollada en el marco de estudios de maestría cursados en el período 2013-2015 en el Programa de Posgraduación en Educación de la Universidade Federal de Santa Catarina (UFSC), Florianópolis SC, con la orientación del Dr. Jaison José Bassani, contando con la beca "docentes CAPES/Udelar" y el apoyo del Instituto Superior de Educación Física (ISEF) de la Universidad de la República (Udelar). El trabajo se inscribe en la línea de investigación "Educación, sociedad y tiempo libre" de ISEF/Udelar en estrecha relación con el Núcleo de Estudos e Pesquisa Educação e Sociedade Contemporânea (UFSC/Florianópolis-SC).

${ }^{2}$ José Batlle y Ordóñez, como cara visible de la principal fuerza política con la que se inaugura el siglo XX en Uruguay, alcanza la presidencia durante los períodos 1903-1907 y 1911-1915. Adhiriendo a Caetano (2011), el batllismo aparece como "proyector-sintetizador" de su época, embanderando una serie de reformas para forjar el "país modelo", tomando como referencia la Europa capitalista, recibiendo fuertes influencias americanistas y manteniendo una mirada atenta a la vez que competitiva con la ciudad vecina de Buenos Aires (SCARLATO, 2015). Ha sido, y continúa siendo, foco de atención tanto para el ámbito político como académico uruguayo.
} 
laicos promulgados en el período, sintetizados de manera ejemplar por el batllismo. Se analiza este proyecto de plazas, liderado inicialmente por el primer Presidente de la CNEF, Juan Arturo Smith, señalando aspectos que se pretendieron distintivos y "superadores" respecto al proyecto americano de Playgrounds, así como algunas de las fuertes influencias recibidas por los misioneros de la YMCA.

Las principales fuentes que se abordan en este artículo son actas de sesión de la CNEF entre los años 1911 hasta $1918^{3}$, la Revista Uruguay-Sport del año $1918^{4}$ y la publicación "Plazas Vecinales de Cultura Física. Orígenes, propósitos, normas morales y de buenas costumbres" del año 1913, con autoría de Juan Arturo Smith como presidente de la CNEF5. También se trabajó con el libro de Mero, E. B. “American Playgroud” del año 1908, tomado como antecedente e insumo para la elaboración del proyecto de plazas antes mencionado. Por último, se utilizaron publicaciones del diario "El Día" del año 1913 .

\section{UNA CULTURA FíSiCA A LA TALLA DE UNA NUEVA CIUDAD. LA COMISIÓN NACIONAL DE EDUCACIÓN FÍSICA EN CAMPAÑA}

\footnotetext{
${ }^{3}$ La CNEF fue un organismo encargado del fomento e impulso de la cultura física del país que funcionó hasta el año 2000, donde sus competencias son trasladadas a la órbita ministerial. Estaba integrada por 11 miembros y se reunía quincenalmente. Hasta el año 1915, cada sesión fue registrada de forma manuscrita por el secretario de la Comisión, a partir de ese año pasaron a ser escritas por máquina de escribir. Actualmente los libros de actas se encuentran disponibles en el archivo documental de la Secretaría Nacional de Deportes, dependiente del Poder Ejecutivo.

${ }^{4}$ Fue una publicación editada por la propia CNEF entre los años 1918 y 1926. Eran publicadas allí actas de sesión de la CNEF, material para la formación de profesores, entre otros asuntos de competencia de la Comisión. Estas publicaciones se encuentran disponibles en la Biblioteca del ISEF/Udelar, Montevideo.

${ }_{5}^{5}$ Juan Arturo Smith fue el encargado de editar esta publicación de 48 páginas que reúne extractos presentes en las Actas de sesión de la CNEF, donde fue expuesto y discutido el proyecto de plazas. Amerita señalar el gran protagonismo con el que se presenta en las actas la figura de Smith durante los dos primeros años de la CNEF (1911-1913), presentando avances escritos del proyecto de plazas que eran discutidos y aprobados en sesión (generalmente con muy pocos cambios a lo que proponía Smith). La publicación comprendía un primer apartado de "conceptos", donde se conceptualizaba Educación Física, Cultura Física, Cultor y Ejercicio Físico. Luego, se continuaba con las siguientes secciones: "Orígenes y propósitos de las plazas", "Propósitos en el órden físico y moral", "Normas morales y de buenas costumbes", "Normas higiénicas". Luego se exponía un "Reglamento General Provisorio de las Plazas Vecinales de Cultura Física" integrado por cinco capítulos, y un "Reglamento interno provisorio". Por último, "Edificios y aparatos esenciales que deben formar parte de una Plaza Vecinal de Cultura Física". Esta publicación fue encontrada en la Biblioteca Nacional de Montevideo.

${ }^{6}$ Este diario, publicado desde el año 1886, fue donde José Batlle y Ordóñez expuso y defendió su pensamiento en materia política, económica y social. Destinó reiteradas columnas a combatir el militarismo de Máximo Santos y, ya en el gobierno, expuso sus ideas sobre el desarrollo de la industria del país (tendiente a ganar independecia respecto a las inversiones extranjeras), la defensa del movimiento obrero especialmente en relación al proyecto de ley de regulación de la jornada laboral, seguridad social, entre otros debates del período. En estos artículos debatía directamente con publicaciones de los diarios "El Siglo", "La Nación", "La Situación", "La Democracia", entre otros (QUIJANO, 1969). Estos diarios se encuentran disponibles microfilmados en la Biblioteca Nacional de Montevideo. Varios de los artículos también fueron reunidos en la publicación mensual nº 32 de Cuadernos de Marcha, dedicada a José Batlle y Ordóñez, organizada por Carlos Quijano (1969).
} 
Entre las novedades a las que asiste Uruguay con la llegada del siglo XX, se advierte el surgimiento del batllismo como principal fuerza política que, no sin disputas y oposiciones, embandera el proyecto de reformas para impulsar el "país modelo" en referencia a Europa, pero recibiendo fuertes influencias americanistas y manteniendo una mirada atenta y competitiva a la vecina ciudad de Buenos Aires. El batllismo se focalizó en la ciudad de Montevideo, como el único centro político-burocrático, comercial e industrial del país, tomándolo como laboratorio de las nuevas políticas reformistas impulsadas por el sector. Montevideo no era estrictamente una "gran ciudad", sin embargo, recibía directa influencia de las metrópolis europeas y pretendía tornarse una ciudad “'modélica', en términos de expresión acabada de modernidad, belleza y hasta grandiosidad republicana" (CAETANO, 2011, p. 25). Entre finales del siglo XIX y principio del XX, la ciudad no sólo se exandió sino que cambió su identidad urbana, emprendimientos particulares y sin planeamiento general de la ciudad se combinaron con las nuevas proyecciones por parte del Estado, que procuraban anticipar y detener el avance impulsivo de los primeros (CAETANO, 2010). En el período inicial de la presidencia batllista fueron explicitadas las voluntades del sector de refundar Montevideo, teniendo por objetivo transformar lo que restaba del viejo siglo XIX para dar paso a la nueva ciudad moderna de vocación urbana. "Embellecimiento" urbano hizo confluir dentro de la propuesta del primer batllismo -no sin enfrentamientos con otros sectores políticos y económicos del país- los proyectos de "ciudad verde e integrada", "ciudad capital" y "ciudad balnearia" (CAETANO, 2010, p. 25) y, de forma simultánea, la promulgación de una vasta serie de reglamentaciones y ordenanzas municipales?. Lo que Caetano (2010, p. 25) llamó "ciudad batllista", fue el escenario para el desarrollo de una ciudadanía con perfiles republicanos, materializada y expandida a partir de los nuevos "templos laicos":

\begin{abstract}
la nueva Montevideo debía confirmar la centralidad de la política, expresar y a la vez habilitar un civismo activo y participativo, integrar el hábitat de los ciudadanos desde el protagonismo y la simbolización protectora del Estado. Al mismo tiempo, debía traducir del modo más concluyente la noción genérica de predominio de lo público sobre lo privado y del Estado sobre el mercado, "monumentalizando" valores y virtudes cívicas, todo lo que debía encarnarse en grandes "templos laicos" propios de una "religión civil” que dominara en el espacio público. (CAETANO, 2010, p. 25).
\end{abstract}

Una de las políticas novedosas impulsadas por el batllismo fue la creación de la Comisión Nacional de Educación Física (CNEF) ${ }^{8}$, instalada el 7 de julio de 1911, como

\footnotetext{
${ }^{7}$ Las primeras legislaciones urbanísticas limitando las construcciones a libre disposición de los privados, fueron de la primera década del siglo XX, junto con la creación de la Sección de Embellecimiento de Pueblos y Ciudades del Ministerio de Obras Públicas, del año 1911 (CAETANO; PÉREZ; TOMEO, 2010).

${ }^{8}$ La Ley prescribía la integración de la nueva comisión encargada de la cultura física del país por el Rector de la Universidad, el Inspector Nacional de Instrucción Pública, el presidente del Consejo Nacional de Higiene y el
} 
organismo dependiente del Poder Ejecutivo (PE) ${ }^{9}$. En 1906, el entonces Presidente José Batlle y Ordóñez, presentó un proyecto de ley de institución de los juegos atléticos anuales, destinados a "todos los habitantes del país, no profesionales" (CNEF, 1949, p. 5). Este proyecto de ley permaneció sin sanción hasta el segundo período de gobierno batllista donde fue discutido y reformulado en el marco de la Comisión de Fomento de la Honorable Cámara de Representantes. Los recursos se destinaron, además de a la realización y premiación de los juegos atléticos anuales, al "fomento de la educación física y en la instalación de plazas de juegos populares, establecimiento de baños públicos y todas las otras mejoras que responden al mismo fin" $"$. Así fue argumentado por el entonces Ministro de Instrucción Pública, Dr. Antonio Cabral:

Vuestra Comisión se inspira en las conclusiones unánimemente aceptadas hoy por los higienistas y los pedagogos: la tendencia de la educación física no debe ser la de formar atletas ni individuos excepcionalmente dotados sino, y con especialidad, la de elevar el nivel medio de la capacidad y la resistencia física general. (CNEF, 1949, p. $3)$.

El nuevo organismo encargado del "fomento" e "impulso" de la cultura física del país, tenía un claro objetivo que lo distanciaba de otras instituciones preexistentes vinculadas a los sports y a la cultura física en el país. La CNEF tenía por cometido fomentar e impulsar la cultura física del país, tendiendo a "popularizar los ejercicios gimnásticos y hacerlos accesibles a la mayor parte de la población, que hoy no los practica" (CNEF, 1911, p. 18).

En las primeras sesiones, la CNEF se ocupó de delimitar su ámbito de actuación, definiendo prioridades respecto a los fines preestablecidos por la ley. Es posible percibir en las actas de los primeros años, un gran protoganismo del Presidente de la Comisión, Juan Arturo Smith $^{11}$, presentando la mayoría de los informes que establecieron la agenda de trabajo de la CNEF. Sin embargo, puede observarse que este lugar de protagonismo comienza a ser objeto de puja sobre el final del primer período (1911-1913) y, habiendo concretado la creación de la

Director de la Academia Militar. Junto a estos miembros ex-oficio, el PE nombraría "personas de competencia" hasta completar los once integrantes previstos. Además de los cuatro miembros "ex oficio", el PE nombraría a Juan A. Smith, Rodolfo de Arteaga (Presidente da Asociación Cristiana de Jóvenes), Pedro Towers (Presidente de la Liga Uruguaya de Football), Hector R. Gómez (Presidente del Círculo de Armas), Manuel Aubriot (Presidente del Montevideo Rowing Club Uruguay), Carlos Sturzenegger y José María Zamora (Presidente del Touring Club Uruguayo). (CNEF, 1911-14, p. 1). La CNEF estaría así integrada por dirigentes de aquellos clubes que, fundados en las últimas tres décadas del siglo XIX, habrían tenido un rol protagónico en el desarrollo de los sports en Uruguay. Cf. Pérez Monkas (2015).

${ }^{9}$ Ante la promulgación de la Ley $\mathrm{n}^{\circ} 3.789$.

${ }^{10}$ Informe de la "Comisión de Fomento" (13 de noviembre de 1906), transcripto en el "Plan de Acción" de la CNEF (1949).

${ }^{11}$ Ex-dirigente del Partido Nacional censurado tras apoyar la candidatura de Batlle y Ordóñez a la presidencia en 1903. Habría fundado junto a Batlle la "Sociedad de Tiro y Gimnasio Montevideano" (1887) (GUTIÉRREZ CORTINAS, 1991). 
primera "Plaza vecinal de cultura física", Juan Arturo Smith renuncia a su función. Nuevamente llama la atención que en el Plan de Acción del año 1923 de la CNEF, cuando el entonces Director Técnico de la CNEF, Julio J. Rodríguez, se refiere al proyecto de plazas, no se menciona a Smith como figura relevante en este proceso. Julio J. Rodríguez fue el segundo Diretor Técnico de la CNEF, permaneciendo desde 1920 hasta 1960, declarándose él mismo sucesor de su maestro norteamericano y primer director técnico de la CNEF (1913-1918), Jess T. Hopkins. Este último era maestro en Educación Física graduado en la Universidade de Springfield Còllege de la YMCA norteamericana. En el año 1912 se radicó en Uruguay como encargado del recién creado Departamento de Educación Física de la Asociación Cristiana de Jóvenes (ACJ), fundada en 1909 (DOGLIOTTI, 2013). A partir de un convenio de subvención de la ACJ por parte de la CNEF, se propuso a Hopkins como director técnico de la CNEF (CNEF, 1911, p. 209), con una responsabilidad directa sobre el funcionamiento de las prazas de cultura física y sobre la primera formación de profesores. Esas tareas fueron retomadas por J. J. Rodríguez que, facilitado por Hopkins, inicia estudios universitarios de Educación Física en la Universidade de Springfield ${ }^{12}$ (Cf. DOGLIOTTI, 2012, 2014).

La nueva Comisión Nacional se encargaba de llevar adelante una campaña por la educación física haciéndo llegar los hábitos saludables impartidos por ésta a cada rincón del país ${ }^{13}$. La publicación, difusión y propaganda constituían un elemento esencial en la campaña de la educación física estatal, conducida entonces por la CNEF. Sería la herramienta que permitiría relacionar las asociaciones de cultura física existente, "unificando la acción y los métodos", informar acerca de las actividades para la población, así como procurar recursos que posibilitasen la formación de nuevas asociaciones o ámbitos de expansión de la cultura física a partir de la propia CNEF. Es decir, la propaganda no sería sólo un medio para transmitir información, no apuntaba apenas a sugerir, propagar, hacer comprender. Cada vez más, la imprenta se va a constituir en un mecanismo de persuación, estímulo, concreción. Como señala

\footnotetext{
${ }^{12}$ En la sesión de la CNEF del dia 1 de agosto de 1917 se anuncia que el Sr. Julio J. Rodríguez viajaría por estudio a "Norte América", permaneciendo 4 años para obtener la titulación de "Profesor de Cultura Física" en la Universidade de Springfield. La CNEF apoyaría sus estudios destinando \$240 para los pasajes así como le entregaría fotografías de la Comissão Técnica (CNEF, 1915, p. 233).

${ }^{13}$ En el Art. 6 de la referida Ley se detallan los siguientes fines: Organizar todo lo referente a los concursos anuales en la República. La formación de asociaciones de cultura física racional. Relacionar las asociaciones nacionales existentes, entre sí y con las extranjeras, unificando la acción y los métodos. Publicar revistas especiales y libros de propaganda popular. Fomentar la fundación de plazas de juegos, gimnasios, baños públicos y stands de tiro. Recabar de las autoridades, de las corporaciones y de los particulares, asignaciones de fondos, donativos y otros recursos para impulsar la cultura física en el país. Organizar conferencias públicas en los establecimientos nacionales para los padres de familias, sobre higiene infantil. Combatir las causas de deterioro físico, en la infancia y juventud, de todas las clases sociales. Proyectar un plan racional de educación física obligatoria en las escuelas de instrucción primaria y en los establecimientos de instrucción secundaria (URUGUAY, 1911).
} 
Schneider, refiriendo a las ideas de Darnton (1997), "a imprensa deve ser compreendida como força ativa na história, uma vez que ela ajuda a dar forma aos eventos que registra; nesse sentido, ela atua como um dos principais ingredientes da construção de novas culturas" (SCHEIDER, 2004, p. 40). El diario popular fomentado por el batllismo sería una de las vías de esta campaña. En "El Día” se publicaba una sección denominada "Movimiento sportivo", en la cual, al menos en el año 1913, las referencias al Turf (en el "Hipódromo de Maroñas") y al football nunca faltaban (EL DÍA, 1913), a su vez, eran publicados artículos sobre el trabajo de la CNEF. Se difundían desde discusiones y resoluciones de la Comisión, noticias de las actividades impulsadas, indicando las vías de inscripción a las mismas, hasta prescripciones médicas para prevenir y combatir la tuberculosis. Desde el primer período de funcionamiento de la CNEF, se manifiesta la necesidad de editar y publicar una revista propia del organismo. Esta iniciativa sería retomada con la incoporación a la CNEF del Sr. Ghigliani, el 14 de setiembre de 1914 (CNEF, 1911, p. 323), quien pasa a ser responsable de la publicación oficial de la Comisión: Revista “Uruguay-Sports”, editada a partir del año 1918 (GUTIÉRREZ, 1991, p. 33).

\section{ESPACIOS POPULARES DE CULTURA FÍSICA ${ }^{14}$}

Las plazas de cultura física "no representan una novedad moderna", Smith (1913, p. 5) afirmaba que "desde muy antiguo, sociedades o comunas, se ocuparon de establecer, en centros populosos, plazas o sitios baldíos a los cuales concurría el pueblo llevando sus niños, para jugar y correr al aire libre, proporcionándoles algunos aparatos de recreo, de primitiva y simple construcción". Sin embargo, estas "creaciones empíricas" tenían otros fines que no alcanzaban el "concepto moderno de las plazas vecinales de cultura física [, a saber,] proporcionar al hombre no sólo un centro recreativo, sino la enseñanza racional y científica de todos aquellos ejercicios que contribuyan a la mejora, embellecimiento y vigorización de la raza" (SMITH, 1913, p. 6). En aquel antiguo ideario "para nada entraba en sus propósitos usar las plazas, como medio exquisito, tal vez, y sin tal vez, el mejor de todos los preconizados en épocas recientes para perfeccionar la raza humana física y moralmente" (SMITH, 1913, p. 6). La versión

\footnotetext{
${ }^{14}$ Las investigaciones que anteceden a este trabajo, referentes a la educación del cuerpo en Uruguay (DOGLIOTTI, 2012; RODRÍGUEZ, 1999; 2012) abordan el término cultura física, advirtiendo su centralidad en el proceso gestacional de la EF. En una misma línea, encontramos referencias al término "cultura física" en países vecinos. En el caso de Brasil, Taborda de Oliveira y Linhales (2011, p. 362-362) rastrean este término en las fuentes utilizadas en sus trabajos, especificamente en algunas tesis provenientes de Rio de Janeiro y en las presentadas en la I Conferência Nacional de Educação (Curitiba, 1927). En el caso de Argentina, tanto Ainsentein (2008) como Scharagrosky $(2011,2015)$ han referido y dedicado atención al término, así como han analizado las formas específicas que adquirió la cultura física en ese país. Estos trabajo coinciden, de modo general, con la identificación del uso del término en el período comprendido entre las últimas décadas del siglo XIX y primeras del siglo XX.
} 
moderna de estas nuevas plazas, que se inauguraba en Montevideo como experimento de la CNEF a ser replicado en cada centro poblado de Uruguay, tenía su referencia en los países de Europa y "muy especialmente en Estados Unidos", donde "los gobiernos de los estados y los municípios gastan en sus instalaciones sumas enormes" (SMITH, 1913, p. 7). La publicación de Smith (1913) citaba al libro de "American Playgrounds", de E. B. Mero (1908), explicitamente para referirse a las cifras que aquel pais invertía en el proyecto. Mientras, "en los últimos años que precedieron al 1909, se gastaron en Estados Unidos CINCUENTA Y CINCO MILLONES DE PESOS en sus playgrounds" (SMITH, 1913, p. 7), la CNEF

Con sus escasísimos recursos ( $\$ 50.000$ anuales), y sin querer desatender las múltiples obligaciones que su complejo y vasto cometido le imponen, ha querido crear las plazas vecinales de cultura física, y en su iniciación ha querido ir más allá y ha ido, que su sabia hermana del norte [...] Nosotros damos a nuestras plazas una organización mucho más perfecta y mucho más amplia. (SMITH, 1913, p. 10-11).

En la exposición de Smith, las plazas de cultura física en Uruguay "superaban" a los playgrounds de los Estados Unidos en dos principales aspectos. El primero, "no son sólo para niños o los adolescentes, a ella también pueden concurrir las madres, los padres, los jóvenes o ancianos; a presenciar los ejercicios de sus hijos, o para hacerlos ellos mismos, que para todo ha previsto la [CNEF]" (CNEF, 1913, p. 11). El segundo refería a la "direción organizada" que incorporaba la versión uruguaya:

\footnotetext{
Nuestras plazas, cuentan además con directores y profesores competentes que dirigen racionalmente los ejercicios de esos centros, fijando a cada cual aquel o aquellos que convengan a su salud o a su desarrollo, e instruyéndoles en los ejercicios reglamentados o libres, de manera de obtener el más favorable éxito en pro de su perfeccionamiento moral y físico. (CNEF, 1913, p. 11).
}

Las plazas se inscribían en un programa de educación física escolar con el objetivo de mejorar los "inconvenientes de los edifícios escolares [que] ni ahora ni nunca podrán llegar a reunir condiciones de higiene y de espacio al aire libre" (CNEF, 1913, p. 12). En concepto de la $\mathrm{CNEF}$, el programa escolar debía ser siempre un "programa mixo, de educación intelectual y de educación física, quitándole dos horas a la primera para dárselas a la segunda, con el propósito de que los niños puedan concurrir diariamene a esos centros de cultura física al aire libre".

El plano de la plaza prevía también una distribución espacial interna de los asistentes. Como no era sugerido el modelo norteamericano de playground, sería diferenciado un sector para niñas y otro para niños. Dentro de los elementos de "orden y disciplina" dirigidos al sexo masculino el proyecto explicitaba que no estaba permitido "estacionarse en la línea divisoria del campo de las mujeres, ni estacionarse allí cuando estén practicando sus ejercicios o juegos" 
(SMITH, 1913, p. 43). De cada lado de la plaza, se ubicaría "pabellón para baños fríos y calientes". El sector femenino, para "señoras y señoritas" y para "bebes y niñas", debía contar también con un gran "gimnasio higiénico para inverno", "toboggans, escalera, hamacas, paso del gigante, sube y baja", campo para "pelota al canasto, pelota de barrera, para pelota-base", “campitos de arena, arcos y rendas para carreras", entre otros elementos (SMITH, 1913, p. 47). El sector masculino, de mayor superficie espacial, incorporaba una cancha de fútbol. Sin embargo, lo proyectado no sería exactamente lo concretado, aunque se procuraría salvaguardar los principios de organización espacial. Un ejempo de esto, la mayoría de las plazas no contarían con la extensión suficiente como para crear un sector específico para cada sexo, con lo cual serían organizados los horarios para mantener la "distancia debida" entre niños y niñas utilizando un mismo espacio.

Al decir de los miembros de la CNEF, el fútbol sería el primer deporte que se popularizó en el país, era también promovido por el diario "El Día", pero no sin despertar sentimientos ambiguos en los diferentes sectores sociales. La CNEF, pretendía promover la práctica de otros deportes más allá del fútbol pero tenía claro conocimiento del atractivo social de este último. Instalar un espacio para la práctica del fútbol en la plaza sería estratégico principalmente para los "niños y jóvenes que iniciaba sus prácticas futebolísticas en pátios, calles y baldíos montevideanos, no rendían expreso culto a las teorías de la higiene pública” (GONZÁLEZ SIERRA, 1996, p. 218). Otros deportes serían incorporados a la dinámica de las plazas, como se observa en las fotografías y argumentos de la CNEF, fundamentado inicialmente por su valor en tanto ejercicio o práctica recreativa, sin la rigurosidad de las reglas e indumentaria específica. En este sentido, el deporte no parece tener protagonismo aún en el impulso de la primera "plazas vecinales de cultura física", donde todo elemento incorporado por la educación física se justifica por sus beneficios fisiológicos sobre el organismo. Este sería el caso también de los denominados aparatos, como el "paso del gigante", elemento tomado de los playgrounds norteamericanos, incorporado y justificado por sus bondades para el fortalecimiento del tren superior del niño (URUGUAY-SPORT, 1918).

El "quiebre discursivo" que anunciaba Dogliotti (2012), y es retomado por Malán y Craviotto (2013), de sustitución de la gimnástica por el sport, sería estudiado a partir de los textos de Varela y Lamas entre 1874 y 1911, y los discursos de la CNEF, analizados a partir de la revista oficial "Uruguay. Sport” en lo años que fue publicada (1918 a 1926). Sin embargo, ese desplazamiento no parece tan evidente en los primeros años de funcionamiento de la CNEF. Específicamente, a partir de la aproximación a los documentos de creación de los primeros "Gimnasios populares" y al proyecto inicial de Smith de "Plazas Vecinales de Cultura Física", 
"ejercícios y juegos", "libre o reglamentados" seríam las actividades principales de una propuesta de educación física (SMITH, 1913, p 40-43). Los “ejercícios libres” y los "ejercícios racionales y científicos", para una "gimnástica del organismo" (SMITH, 1913, p. 14), van a constituir el centro de la propuesta respecto a la infancia. Además de los ejercicios gimnásticos reglamentados para niños y niñas, las actividades para adolescentes y hombre incluían, además de los anteriores, los “deportes atléticos" pero actuando más como atractivo para alejar a estos de "reuniones malsanas" (CNEF, 1911, p. 149), como otras actividades de la plaza biblioteca o cinematógrafo (SMITH, 1913).

\section{LAS NUEVAS PLAZAS COMO "TEMPLOS LAICOS": UNA CULTURA FÍSICA AL SERVICIO DE LA "RELIGIÓN CIVIL"}

La publicación de Smith "Plazas Vecinales de Cultura Física", de 1913, comienza con una primera sección de conceptos, en la cual se encuentran, entre otros: Educación Física, Cultura Física, Cultor y Ejercicio Físico (p. 4). La Educación Física se presenta como la "ciencia" que va a reunir todos aquellos "conocimientos" tendientes a "perfeccionar las cualidades psíquico-físicas del hombre”, y su propósito: además de "vigorizar y embellecer el cuerpo", es "elevar la capacidad moral e intelectual" para la posesión de las "virtudes" que pueden "adornar un espírito sublime". Respecto a "Cultura Física", es definida como la "acción" que tiende a "cultivar de modo completo el organismo humano" de modo "harmónico, racional y científico", de acuerdo a las "preescripciones dictadas por la Educación Física" (SMITH, 1913, p. 4). Me gustaría señalar aquí al menos dos elementos.

En primer lugar, más allá del carácter distintivo de la Educación Física como ciencia, no hay una clara distinción y jerarquización en relación al concepto de cultura física, en la medida que esta última implica la acción de "cultivo" del organismo siguiendo los presupuestos científicos de la primera. Las prácticas a ser integradas a la cultura física del país, son aquellas que siguen las preescripciones científicas, direccionadas al perfeccionamiento del organismo: la "más perfecta de las máquinas, la máquina del hombre" (CNEF, 1911, p. 33), pero sin agotarse en este fin. Las carreras ciclistas y a pié serían algunas de las primeras prácticas impulsadas por la CNEF, cuya justificación se expone a continuación:

La carrera a pie, las marchas rápidas o forzadas, las de resistencia, "el alpinismo" como todos los demás ejercicios que constituyen la educación física, no son meros constituyentes de perfecciones materiales, las que profesando casi un culto por esa educación y amor a ella "cultores militantes", lo somos porque es en nuestra convicción profunda que ella no tiende solo al embellecimiento y vigor de la raza, 
como simple condición de perfeccionamiento "plástico" permítaseme la dicción sino también y en primer término por lo que perfecciona el sentimiento, moraliza las costumbres, forma el carácter, desarrolla la bondad, acrecienta el cariño, prolonga el altruismo y la abnegación en favor de sus semejantes. (CNEF, 1913, p. 37).

Como advierte Dogliotti (2012, p. 131), la "Cultura Física", que emerge en los novecientos, no se aleja de los atributos desarrollados anteriormente por la educación física:

La cultura física se erige como un modelo a desarrollar e inculcar en cada uno de los sujetos para convertirlos en ciudadanos, para civilizarlos, pero para esto la educación higiénica es fundamental. [...] La cultura física no implica cualquier práctica corporal sino solo aquellas científicas como la gimnasia, los juegos metodizados y fundamentalmente al aire libre.

Siguiendo a Dogliotti (2012), a partir de su estudio centrado en la formación de profesores de educación física, este cambio semántico está relacionado a otro cambio: la institucionalidad. De la gimnástica, que de modo diferente a los países del norte europeo y de norteamérica, se desarrolla principalmente en el interior del sistema educativo escolar, la cultura física configurada en el proceso gestacional de la CNEF:

Remite, a diferencia de la "gimnástica", a un campo más amplio de prácticas
corporales y también de acción, ya no solo dirigida a los escolares sino a toda la
población. Pero en ambos significantes lo físico o corporal remite al cuerpo puramente
orgánico, biológico. [...] la cultura física remitía a ciertas prácticas corporales
instauradas a partir del desarrollo de "las ciencias" y se oponía a otras, como el circo
[...] En el Novecientos, la "cultura" se identificaba con civilización [...] No hay casi
diferencias de sentido importante en relación a "cultura física" y "educación física"
[...] Aunque pareciera que el término "educación física" fuera más utilizado por los
actores formados en el propio campo, Jess Hopkins y Julio J. Rodríguez, que en los
discursos de los actores políticos ya nombrados". (DOGLIOTTI, 2012, p. 301).

Quizás esta última indicación de la autora explique en parte la permanencia y vigencia de ciertos discursos y no otros en el campo de la Educación Física. Mientras Smith representaba un apasionado y comprometido con el desarrollo de la cultura física del país, Jess Hopkins y Julio J. Rodríguez representaban la "cientificidad” en el ámbito de la Educación Física, siendo los primeros diplomados en el área en el ámbito de la CNEF. Como fue mencionado anteriormente, el estadounidense Hopkins (Maestro en Educación Física graduado en la Universidade de Springfield Còllege da YMCA norteamericana) fue radicado en Uruguay en el año 1912, como encargado del recién creado Departamento de Educación Física de la Asociación Cristiana de Jóvenes (ACJ), fundada en 1909 (CNEF, 1911, p. 211; DOGLIOTTI, 2013). En la sesión del día 12 de diciembre de 1912, se realizó un ajuste de las competencias de la figura del Diretor Técnico de las plazas. El propio Smith, quien ejercía la función de Presidente en ese entonces, propuso que Hopkins fuese el director técnico de la primera "plaza 
vecinal de cultura física”. Resaltaba en él la competencia para el cargo que combinaba formación acreditada y la personificación del "cultor":

Las recomendaciones de que viene procedido el Sr. Hopkins, sus títulos normalistas y su actuación como profesor en Estados Unidos, lo recomiendan como persona de especial competencia para el desempeño de su cometido y como hombre de condiciones morales y de carácter ejemplar para el desempeño del cargo [...] el señor Hopkins es un cultor que más que profesional ejerce sus funciones como un apostolado y en el caso actual no hace cuestión de interés. (CNEF, 1911, p. 209-211).

A este respecto, la segunda observación sobre los conceptos presentados por Smith (1913), es en relación al término cultura física como la acción de "cultivar" el organismo y la Educación Física. La metáfora agricultora adquiere fuerza en las fuentes que se refieren al término, principalmente al aludir a la infancia: "vivero este del cual extraeremos los elementos necesarios para constituir en un próximo futuro una virtuosa inteligente raza sana y vigorosa", en palabras de Batlle y Ordóñez manifestando su apoyo directo a las iniciativas de la CNEF (CNEF, 1911, p. 50-52). También sería enfatizado por el Director de Instrucción Pública, Alejandro Lamas, cuando expuso las prioridades que la CNEF debería atender en relación al uso de las nuevas plazas: "Para que la educación física dé todo su fruto deberá comenzar en la infancia" (CNEF, 1911, p. 315). Con especial énfasis en los niños sometidos a las condiciones de pobreza, más suceptibles de modelar, "los adultos sólo entran en un orden y categoría inferior" (CNEF, 1911, p. 316). El problema pedagógico es asunto ahora del "servicio" de la educación física estatal. Así como las plazas, cualquier otra medida en relación a la seguridad de la infancia sería meritoria de ser implementada por parte de esta comisión. La conducción de las conductas requiere mecanismos contínuos y eficaces de intervención, captura y producción. El "cultor" como aquel que dedica su accionar al "cultivo de la Educación Física" (SMITH, 1913, p. 4), tiene la misión de "cultivarse" constantemente, así como de dedicar sus fuerzas al "cultivo" de los otros. Como indica Rodríguez (2012, p. 177):

\footnotetext{
El ciudadano modificará sus prácticas corporales, sus hábitos, solamente si comprende que aquello encierra un sentido no solo para él, individualmente, sino para la sociedad toda. Al mismo tiempo, lo que las instituciones proponen como "cultura física" debe ser posible de integrar a la biografía, a lo cotidiano [...] Se trata de que el sujeto entre en nuevo tiempo, proponiendo una nueva institución que regule el mundo de la vida cotidiana, se trata en definitiva de que el tiempo sea el tiempo del progreso, de la producción, del crecimiento ilimitado, del control de la naturaleza, de la eficacia y la eficiencia.
}

El proyecto de plazas prevía un extenso listado de normas morales e higiénicas a ser integradas, corporificadas por el "cultor", las segundas eran detalladas del 1 al 43 bajo el título “No beses ni te dejes besar!": 
$1^{\circ}$ Sed siempre ordenado en tu modo de vivir.

$2^{\circ} \mathrm{El}$ trabajo y el descanso son igualmente necesarios para mantenerse con buena salud.

$3^{\circ}$ Después del ejercicio un baño, después del alimento un pequeño descanso, después del descanso el sueño. [...]

$9^{\circ}$ Mantiene tu cuerpo en perfecto estado de limpieza. La piel pulida no es sólo un embellecimiento del hombre, sino que así nos libera de múltiples enfermedades.

$10^{\circ}$ Lávate las manos a menudo, muy bien y con jabón antes de comer y tocar los alimentos.

$11^{\circ}$ Cuando menos una vez por semana en invierno, deberás darte un baño de agua tibia, y jabonarte de pies a cabeza. En verano báñate, cuando menos, una vez por día, en agua tibia o fría, o en el mar. No tomes el baño si no te sientes bien, ni cuando tengas la comida en el estómago, ni cuando estés sofocado o transpirado.

$12^{\circ}$ Los baños de limpieza e higiene deben ser tibios. Empieza por mojarte bien antes de jabonarte, quítate el jabón con agua tibia y baja la temperatura de ésta gradualmente, hasta que los poros de la piel se cierren nuevamente, así evitarás resfríos. [...]

$19^{\circ}$ Esfuérzate siempre en respirar por la nariz; en un ambiente polvoroso es esto una costumbre que preservará tus pulmones de enfermedades.

$20^{\circ}$ Mantente siempre derecho. La posición recta da un aspecto bello y hace al cuerpo más fuerte y resistente.

$21^{\circ}$ Aspira a diario, muy especialmente de mañana, aire puro, forzándolo hasta lo más recóndito de tus vías respiratorias. Ten cuidado en no hacerlo en lugares mal sanos, donde se haya dormido o donde haya enfermos. Hazlo en las playas, plazas o en los parques, u otros lugares igualmente sanos. Esto fortalece los pulmones, ensancha el tórax, y oxigena la sangre, expulsando del cuerpo materias gastadas o malsanas.

$22^{\circ}$ Cuando leas, escribas o hagas labores manuales siéntate, como se te ha enseñado en la escuela.

$23^{\circ}$ Los ejercicios físicos que hagas, deben ser cuidando las prescripciones de los profesores de cultura física.

$24^{\circ}$ Sed prudente al jugar y has que el juego no degenere jamás en actos groseros que perjudiquen a tus compañeros y a ti. [...]

$38^{\circ}$ Antes de resolver a adoptar una profesión, consulta al médico si tu cuerpo, en general, o si tus ojos, especialmente, te permiten adoptarla.

$39^{\circ}$ Abstente de bebidas alcohólicas, especialmente de aguardientes. El uso habitual del alcohol no solo enferma al hombre, sino que lo hace malo. Casi siempre los delincuentes son bebedores. Para los niños cada gota de alcohol es veneno.

$40^{\circ}$ El uso del tabaco, en la niñez, produce grandes y dañosas perturbaciones en el organismo.

$41^{\circ}$ No leas libros malos o muy emocionantes, corromperán tu cuerpo y tu alma.

$42^{\circ}$ Domínate a tiempo. Que los caprichos y los deseos no te manejen. No te abandones a pensamientos melancólicos o de tristeza. Un trabajo serio y los ejercicios físicos te quitarán los disgustos. Un humor igual y pacífico te asegurarán de la mejor manera la salud del cuerpo y del alma.

$43^{\circ}$ Cultor, si alguna de esas reglas higiénicas no fuesen por ti entendidas acude a tus profesores que te las aclararán. (SMITH, 1913, p. 20-26).

El cultor, aquel señalado en la figura de Hopkins, entrega su vida por una misión, la de predicar con el ejemplo las conductas establecidas por los "pedagogos e higienistas", vía Educación Física. Esta conducción e integración de hábitos morales e higiénicos será acompañada y evaluada por medio de los exámenes médicos y psicológicos, midiendo, observando y describiendo los efectos sobre el organismo. Como indica Castro (2012, p. 414), a partir de la obra de Foucault, "en Occidente, no se llega a ser individuos sino a través de estos procesos de subjetivación que toman forma en las prácticas del gobierno". En otras palabras: 
El hombre occidental se individualiza por intermedio del pastorado en la medida en que éste lo conduce a su salvación que fija para siempre su identidad, lo somete a una red de obediencias incondicionales, le inculca la verdad de un dogma en el momento mismo en el que le arranca el secreto de su verdad interior. Identidad, sujeción, interioridad: la individualización del hombre occidental durante el largo milenio del pastorado cristiano se produjo al precio de la subjetividad. Por subjetivación. Es preciso llegar a ser sujeto para convertirse en individuo (en todos los sentidos de la palabra 'sujeto'). (FOUCAULT, 2011, p. 369-370).

Asimismo, siguiendo a Foucault (1977, p. 5), este proceso de individuación propio de las sociedades capitalistas no opera simplemente por la conciencia o la ideología sino que se ejerce sobre el cuerpo, entendido como "lo biológico, lo somático".

La "cultura física" que se promovía a partir de las políticas de Estado, especificamente desde las iniciativas de la CNEF, tendría influencia directa de las iniciativas de los representantes "misioneros" de la YMCA en Uruguay. Además de la participación del Sr. Towers, Presidente da ACJ de Montevideo, como miembro designado por el PE a la CNEF, se integraba la directa participación de Hopkins en la dirección técnica de las nuevas plazas. Una carta de Hopkins dirigida a la YMCA, organismo norteamericano que representaba la “cristiandade muscular" ${ }^{15}$, resulta ilustrativa de la recepción de Batlle y Ordónez a los ideales de este organismo, aún cuando se trataba de quien "odia todo lo que save a cristianismo":

Conard $^{16}$, nuestro secretario y un graduado de la Universidad de Illinois, y Monteverde $^{17}$, su asociado, un uruguayo muy influyente, han sentado las bases para un maravilloso trabajo de la asociación en este pequeño pero importante país. Hablando del país, no puedo menos que describirlo como hizo el último historiador sudamenricano, Dawson: "El pequeño y valiente Uruguay siempre ha tenido y siempre tendrá una influencia en los asuntos de Sudamérica que exceden en proporción a su tamaño". En poco más de tres años, estos dos hombres han construido una membresía de 750 de los cuales 6/7 son uruguayos; tienen en su comisión algunos de los hombres más fuertes de la ciudad; han asegurado el activo interés de la mayoría de los hombres influyentes en el cuerpo diplomático. Monteverde pasó una hora con el presidente hace poco tiempo describiéndole nuestro trabajo y el Presidente odia todo lo que save a cristianismo, pero cuando terminó se fue con el ejecutivo alabando nuestro trabajo. Este Presidente ha designado una Comisión Nacional de Educación Física y el Congreso ha destinado $\$ 50.000$ por año para su trabajo. El Presidente de la Asociación, Mr. Towers, es miembro de esta comisión, y ha aceptado la designación con el solo propósito de usar su influencia para poner al Director Físico de la Asociación en buena relaciones con esta Comisión. Y esto, me complace decirlo, está funcionando muy bien. La Comisión está planificando un sistema de plazas de deportes y justo esta tarde el presidente (chairman) vino en su automóvil para llevarme a inspeccionar el sitio de la primera plaza. Me dio un bosquejo de sus planes y me pidió para reunirse conmigo mañana y ofrecerle las sugerencias y críticas que desee. (HOPKINS, 1912, s/p).

\footnotetext{
${ }^{15} \mathrm{La}$ "cristandad muscular" fue un movimiento religioso-pedagógico idealizado por el reverendo Thomas Arnold, que, a través de una reforma pedagógica, introdujo en las antiguas Public Schools de Inglaterra victoriana una metodologia para alcanzar el ideario del Christian Gentleman (ALBÓ, 2015).

${ }^{16}$ Felipe A Conard, norteamericano, fue fundador en el año 1909 de la ACJ de Montevideo (DOGLIOTTI, 2012, p. 171).

${ }^{17}$ Vice-presidente de la ACJ Montevideo desde su fundación y desde el año 1910 fue su Secretario, dedicaría su vida en esta institución (DOGLIOTTI, 2012, p. 172).
} 
Esta apertura por parte del Estado uruguayo a las iniciativas de la Asociación Cristiana de Jóvenes de Montevideo, siendo incorporados incluso a los propios organismos estatales, determinará una fuerte influencia en la cultura física promovida oficialmente. Un ejemplo de esto es estudiado de modo ejemplar por Malán (2017), quien analiza la incorporación de las prácticas deportivas en las colonias valdenses de Uruguay entre 1920-1970, como parte de un proceso de expansión de la Cristiandad Muscular como doctrina evangelizadora que se extiende más allá de Inglaterra.

\section{REFLEXIONES FINALES}

Las nuevas plazas proyectadas e implantadas por la CNEF se presentan como uno de los nuevos "templos laicos" de la proyectada "ciudad batllista" a la que aludía Caetano (2010), impartiendo prácticas y hábitos para la expansión de la "religión civil" que debía regir y conducir al individuo en el espacio público de una ciudad moderna. Este nuevo discurso "laico" a ser corporificado por medio de principios morales e higiénicos, era producido científicamente por médicos, fisiólogos y pedagogos que formaban parte de la campaña de la educación física. La figura del "cultor" promovida dentro de las plazas se presenta como "deber ser" para practicantes y aprendices, encarnando este ideal de cuerpo moral/higiénico (dos caras de una misma moneda) para el nuevo ciudadano. Las escuelas y las fábricas cumplían con su función ya desde las últimas décadas del siglo XIX, ahora, las nuevas plazas - entre otras medidas de la CNEF - debían ocuparse de la conducción de niños y adultos para la vida pública.

Los nuevos espacios de cultura física engendran, organizan y sistematizan un conjunto de prácticas de intervención y saberes sobre el cuerpo y el tiempo libre, expandiendo la nueva "religión civil" que debería, siguiendo el ideal batllista, dominar el espacio público. Sin embargo, ¿cuáles serían las características distintivas de esa “nueva religión”? ¿Qué cambios implicaría en la/s forma/s de educar el cuerpo y, particularmente, en la educación física? Los elementos antes expuestos, dan cuenta de la importante influencia recibida por la YMCA en el proceso gestacional de la CNEF en las primeras décadas del siglo XX y de la adopción de prácticas impartidas por esta organización, legitimadas bajo el discurso secular de la ciencia médicina y fisiología-. A su vez, la estrecha relación entre la CNEF y la YMCA (anunciada y abordada por Doglotti y Craviotto/Malan, 2015) representa un elemento interesante para pensar, formulado aún como hipótesis primaria, la cultura física como forma secularizada (en el sentido agambeniano del término) de la "Muscular Christianity". 


\section{REFERENCIAS}

ALBÓ, J. A. La reforma pedagógica de Thomas Arnold y el papel de la iglesia angelicana en la creación de los primeros clubes de fútbol en Inglaterra (1863-1890). Materiales para la Historia del Deporte, 13, 2015.

CAETANO, G. La República Batllista. Montevideo: Ediciones de la Banda Oriental, 2011.

; PÉREZ, C.; TOMEO, D. Baroffio, arquitectura y primer batllismo: las bases físicas de un modelo de ciudadanía. En: BAROFFIO, E. Gestión urbana y arquitectura 1906-1956. Montevideo: Facultad de Arquitectura, 2010. p. 23-38.

CASTRO, E. El vocabulario de Michel Foucault. Un recorrido alfabético por sus temas, conceptos, autores. Buenos Aires: Universidad de Quilmes, 2004.

Introdução a Foucault. Belo Horizonte: Autentica, 2014.

CLAPS, M. Batlle. Estudio Preliminar y selección documental. Montevideo: Ediciones de la Casa del Estudiante Martirena y Torres, 1979.

COMISIÓN NACIONAL DE EDUCACIÓN FÍSICA. Actas. Montevideo, ago. 1911-nov. 1914, p. 476.

Plan de Acción de la Comisión Nacional de Educación Física. Julio J. Rodríguez. Montevideo: Imp. LATINA, 1923.

La Educación Física y la Recreación en el Uruguay. Origen. Plan de Acción. Montevideo, Comisión Nacional de Educación Física, 1949.

DOGLIOTTI, P. Cuerpo y currículum: discursividades en torno a la formación de docentes de educación física en Uruguay (1874-1948). 2012. 327f. Tesis (Maestría en Enseñanza Universitaria), Facultad de Humanidades y Ciencias de la Educación, Universidad de la República, Montevideo. Disponible en: $<$ http://posgrados.cse.edu.uy/sites/posgrados.cse.edu.uy/files/tesis_paola_dogliotti.pdf $>$.

Acceso: abr. 2014.

. Acerca de la "Cultura Física" en la revista Uruguay-Sport: Archivos de la CNEF, Uruguay (1918-1926). Rev. Bras. Ciênc. Esporte, Porto Alegre, v. 36, nº. 3, jul./set. 2014.

EL DÍA. Biblioteca Nacional de Montevideo (Archivo microfilmado). Mayo y junio de 1913.

FOUCAULT, M. Historia de la Medicalización. 2da. Conferencia 1974. Educación médica y salud, v. 11, n. 1, 1977, p. 3-25. Defender la sociedad. Buenos Aires: Fondo de Cultura Económica, 2000.

Historia de la sexualidad. Tomo 1: Voluntad de saber. Buenos Aires: Siglo Veintiuno Editores, 2009.

Seguridad, territorio y población. Buenos Aires: Fondo de Cultura Económica, 2011.

Rev. Iberoam. Patrim. Histórico-Educativo, Campinas (SP), v. 4, n. 1, p. 62-79, jan./jun. 2018 
GUTIÉRREZ CORTINAS, E. Sociedad de Gimnasia L’Avenir. 100 años. Montevideo, 1991.

HOPKINS, J. T. Carta a J. H. Mc Curdy, 26 de agosto de 1912. Montevideo, CNEF.

MALÁN, P. Cristiandad Muscular y crisis del ethos valdense: Un estudio discursivo del ingreso del deporte a las Uniones Cristianas de Jóvenes de las colonias valdenses del Uruguay (1920-1970). 2017. 218 f. Tesis (Maestría en Educación Corporal) - Facultad de Humanidades y Ciencias de la Educación, Universidad Nacional de La Plata, Uruguay.

MERO, E. B. American Playgrouds. Boston Mass.: American Gymnasia Co, 1908.

PÉREZ, MONKAS, G. La civilización de prácticas (corporales) deportivas y su inscripción en el discurso escolar. En: $\mathbf{1 0}^{\circ}$ Congreso Argentino y $\mathbf{5}^{\circ}$ Latinoamericano de Educación Física y Ciencias. Universidad Nacional de La Plata, 2013. Disponible en: $<$ http://sedici.unlp.edu.ar/handle/10915/38947>. Acceso: mar. 2015.

QUIJANO, C. (Org.) Batlle. Cuadernos de Marcha, n. 32, diciembre de 1969.

ROCHA, L.; GILES, G. Aprendizaje motor. En: CARBALLO, C. (coord.). Diccionario crítico de la educación física académica. Rastreos y análisis de los debates y tensiones del campo académico de la educación física en Argentina. Buenos Aires: Promoteo, 2015. p. 79-86.

RODRÍGUEZ, R. Saber del cuerpo: una exploración entre normalismo y universidad en ocasión de la educación física (Uruguay, 1876-1939). 2012. 261 f. Tesis (Maestría en Enseñanza Universitaria) - Facultad de Humanidades y Ciencias de la Educación, Universidad de la República, Montevideo. Disponible en: $<$ http://posgrados.cse.edu.uy/sites/posgrados.cse.edu.uy/files/tesis_raumar_rodriguez.pdf $>$. Acceso: mar. 2014.

RODRÍGUEZ, R. Saber do corpo: entre o político e a política. 2015. 204 f. Tesis (Doctorado Interdisciplinar em Ciências Humanas) - Universidade Federal de Santa Catarina, Florianópolis, SC. Disponible en: <http://tede.ufsc.br/teses/PICH0160-T.pdf>. Acceso: jul. 2016.

; SCARLATO, I. Historia del deporte en Uruguay: consideraciones sobre un campo incipiente. En: DE MELO, V. A. O esporte no cenário íberoamericano. Río de Janeiro: 7 Letras, 2015. p. 147-158.

SCARLATO, I. Corpo e temo livre. As plazas vecinales de cultura física em Montevidéu (1911-1915). 2015. 152 f. Disertación (Maestría en Educación) - Centro de Educación de la Universidade Federal de Santa Catarina, Florianópolis, SC. Disponible en: $<$ https://repositorio.ufsc.br/xmlui/bitstream/handle/123456789/158909/337033.pdf?sequence $=1 \&$ isAllowed $=\mathrm{y}>$. Acceso: abr. 2016.

SMITH, J. A. Plazas Vecinales de Cultura Física. Orígenes, propósitos, normas morales y de buenas costumbres; prácticas higiénicas. Comisión Nacional de Educación Física. Reglamentaciones. Montevideo: Talleres gráficos: A. Barreiro y Ramos, 1913.

URUGUAY. Ley $\mathbf{n}^{\mathbf{0}}$ 3.789, 15 jul. 1911. Juegos atléticos y Comisión Nacional de Educación Física. Montevideo: Poder Legislativo. Disponible en: 
$<$ http://www.parlamento.gub.uy/leyes/AccesoTextoLey.asp?Ley=03789\&Anchor=>. Acceso: set. 2013.

Ley $\mathbf{n}^{\mathbf{0}}$ 5.350, 19 nov. 1915. Jornada laboral de ocho horas. Montevideo: Poder Legislativo. $<$ http://www.parlamento.gub.uy/leyes/AccesoTextoLey.asp?Ley=5350.\&Anchor=>. Acceso: mayo 2014. 